\title{
Estudo das propriedades mecânicas do concreto com adição de cinza de casca de arroz
}

\author{
Mechanical strength assessment \\ of concrete with rice husk ash
}

\author{
Adriana Maria Pereira ${ }^{1}$, Carlos Adriano Rufino da Silva ${ }^{1}$, \\ Daniela Cintra de Araújo Queiroz ${ }^{1}$, Maria Júlia Bassan de Moraes ${ }^{1}$, \\ José Luiz Pinheiro Melges ${ }^{1}$, Mauro Mitsuuchi Tashima ${ }^{1}$, \\ Jorge Luís Akasaki ${ }^{1}$
}

\footnotetext{
${ }^{1}$ Departamento de engenharia civil, FEIS-UNESP - Alameda Bahia 550 - CP:15385-000, Ilha Solteira, SP e-mail: adrianapereiradu@gmail.com; cars002@bol.com.br; dacaraujo@yahoo.com.br; maju52@hotmail.com; jlmelges@dec.feis.unesp.br; maumitta@hotmail.com; akasaki@dec.feis.unesp.br
}

\section{RESUMO}

A cura térmica é um processo utilizado para acelerar as reações de hidratação do cimento Portland, em argamassas e em concretos, com objetivo de se obter ganhos de resistência mecânica nas primeiras idades, uma vez que a velocidade das reações químicas de hidratação aumenta com o aumento da temperatura. Nesse sentido, é importante estudar o comportamento de concretos que possuem adições minerais em sua composição. Dentre as adições mais estudadas na composição do concreto encontra-se a Cinza de Casca de Arroz (CCA). Além de ser uma forma de destinar adequadamente este resíduo, e, consequentemente, reduzir os impactos ambientais, tem como principal vantagem os ganhos de resistência, mesmo quando se diminui a quantidade de cimento na mistura. Este trabalho apresenta resultados experimentais de resistência à compressão axial, de resistência à tração por compressão diametral e do módulo de elasticidade para concretos elaborados com CCA, incorporada à mistura em dosagens de 5\% e 10\% (em massa), em substituição ao cimento. A CCA foi produzida por meio da queima não controlada da casca do arroz. Os traços de concreto foram definidos a partir de uma avaliação das propriedades mecânicas de corpos de prova de argamassa com e sem adição de CCA, tendo sido adotados os que apresentaram as maiores resistências. O processo de cura térmica a vapor dos concretos foi desenvolvido em ciclos de 6 horas, a uma temperatura constante de $80^{\circ} \mathrm{C}$. Os resultados mostram um ganho de resistência das amostras com a adição de CCA.

Palavras-chave: cimento Portland, concreto, cura térmica, resistência mecânica, cinza de casca de arroz.

\section{ABSTRACT}

The thermal curing is a process used to accelerate the hydration reactions of the Portland cement in mortar and concrete elements, in order to achieve gains in mechanical strength at early ages, since the temperature acts on the degree of these reactions. On this way, it is important to assess the mechanical behavior of concretes with mineral additions. The rice husk ash (RHA) is a residue that lies among the most studied additions in the concrete composition. The reuse of RHA besides reduce the environmental problems, can cause an increment on the mechanical strength of mortars and concrete, even when is used in partial substitution of Portland cement. This paper presents experimental results of the compressive strength, of the tensile strength (obtained by the split test), and of the modulus of elasticity for concrete prepared with RHA, incorporated into the mixture at dosages of $5 \%$ and $10 \%$ (by mass), in substitution of the cement. The RHA was produced through the uncontrolled burning of rice husk. The concrete mixtures were defined from an evaluation of the mechanical properties of specimens that were made with and without the addition of RHA. The process of thermal steam curing of the concrete was developed in cycles of 6 hours, at a constant temperature of $80^{\circ} \mathrm{C}$. The results showed higher strengths for specimens that were made with the addition of RHA.

Keywords: Portland cement, concrete, thermal curing, strength, rice husk ash. 


\section{INTRODUÇÃO}

O concreto armado é utilizado em grande escala na construção civil brasileira, representando um elevado consumo de cimento, seu principal constituinte. O concreto, já utilizado há quase dois séculos, tem como principal alvo de estudo as suas características mecânicas, seguido pelas preocupações relacionadas à sua durabilidade.

O desenvolvimento de concretos de maior resistência, que permitiram construções mais arrojadas em termos estruturais, elevou a necessidade de se realizarem maiores estudos, não só do comportamento mecânico das peças, mas em especial das características relativas aos materiais constituintes do concreto, além, é claro, da introdução de novos materiais e técnicas construtivas.

Ao longo de décadas, o concreto foi aprimorado com a introdução de aditivos, na forma de plastificantes, retardadores de pega, entre outros, além das adições pozolânicas ou cimentantes constituídas de materiais sólidos inorgânicos muito finos, que compõem a mistura através da substituição do cimento ou somando-se a este na composição do aglomerante.

Entre as adições mais estudadas na composição do concreto estão a sílica ativa, as cinzas volantes e os resíduos agroindustriais, como, por exemplo, a cinza de casca de arroz (CCA), entre outros. As principais vantagens do uso dessas adições são os ganhos de resistência mesmo quando se diminui a quantidade de cimento na mistura; já na microestrutura, contribuem para o desenvolvimento de uma matriz mais definida e uma estrutura geral menos porosa, o que permite maior resistência ao ataque de agentes agressivos, melhorando sua condição de durabilidade aliada a uma maior resistência mecânica.

A cinza da casca de arroz representa $20 \%$ (em massa) da quantidade total de arroz colhida. Segundo os dados do Instituto Brasileiro de Geografia e Estatística - IBGE [1], a produção estimada de arroz em 2014 é de 12.501.317 toneladas. Tanto a casca de arroz quanto as cinzas resultantes da sua queima são fontes de poluição e contaminação, vindo a impactar o meio ambiente e a saúde pública da população, quando gerenciadas de forma inadequada [2]. Assim, a utilização da cinza da casca de arroz como aditivo na composição do concreto é uma forma de valorização deste resíduo, além de oferecer as seguintes vantagens para o meio ambiente: eliminação da necessidade de aterros, redução do perigo tóxico e diminuição da demanda de matériasprimas.

A temperatura de queima da cinza é um fator muito importante para determinar a morfologia da cinza da casca do arroz. A atividade pozolânica da CCA está diretamente relacionada à composição morfológica como também ao tempo de moagem desta cinza. A CCA quando produzida a partir de queima controlada, com temperatura inferior a $600^{\circ} \mathrm{C}$ possui na sua morfologia a presença de sílica no estado amorfo, obtendo desta forma maior reatividade com o cimento e com a cal. Quando queimada a temperaturas muito elevadas, observa-se o surgimento de fases cristalinas na estrutura morfológica, diminuindo desta forma a reatividade com outros componentes, sendo desta forma inviável para utilização em concretos e argamassas []ㅡ.

Conjuntamente com os estudos sobre os materiais, as técnicas de preparo e cura do concreto tiveram grande avanço com a introdução de novas exigências do mercado de construção civil, na qual podemos citar a indústria de pré-moldados.

O uso da técnica de cura térmica a vapor deve ser avaliado de forma a garantir que os efeitos deste tipo de cura sobre o concreto resultem em um material confiável. De modo geral, a cura térmica age sobre as condições de hidratação do cimento, acelerando esse processo e permitindo uma maior rotatividade das fôrmas. Para auxiliar nesse processo de aumentar a velocidade das reações, são utilizados normalmente cimentos que proporcionam maiores resistências em tempos mais curtos, denominados de ARI (Alta Resistência Inicial), e aditivos aceleradores.

Segundo SALVADOR FILHO [4], deve-se considerar o perigo da evaporação de parte da água necessária à hidratação do cimento, que pode provocar a microfissuração da pasta. Este fato, quando não devidamente equacionado, pode tornar o processo ineficaz e não contribuir para a redução do tempo de cura, além de comprometer as propriedades do concreto.

Os dois principais objetivos deste trabalho são: estudar a utilização da cinza de casca de arroz residual em um concreto convencional, caracterizando esse material quanto à sua melhor granulometria e dosagens de incorporação à argamassa e ao concreto; e avaliar a influência da temperatura de cura nas propriedades mecânicas dessas argamassas e concretos. 


\section{MATERIAIS E MÉTODOS}

\subsection{Materiais utilizados}

O cimento usado foi o CPV ARI, cimento de alta resistência inicial.

- Foi utilizada uma areia natural proveniente do leito do rio Tietê, com módulo de finura igual a 2,25 e massa específica aparente de $2,585 \mathrm{~g} / \mathrm{cm}^{3}$.

- A brita usada era de origem basáltica, com dimensão máxima característica de 19mm e massa específica aparente de $2,956 \mathrm{~g} / \mathrm{cm}^{3}$.

- Foi utilizado um superplastificante de base policarboxilato.

A casca de arroz foi fornecida por uma empresa de beneficiamento de arroz da cidade de AndradinaSP e a procedência do arroz era da região de Dourados-MS. Já a Cinza de Casca de Arroz (CCA) foi obtida por meio de queima não controlada, realizada no Laboratório Central de Engenharia Civil, da UNESPCampus de Ilha Solteira.

Após a queima, a cinza era submetida a um processo de moagem, utilizando-se, para isso, um moinho de bolas pertencente ao Laboratório CESP de Engenharia Civil, localizado em Ilha Solteira-SP. A massa total de bolas do moinho era de $52,5 \mathrm{~kg}$ e a quantidade de cinza moída por vez era de $5,5 \mathrm{~kg}$.

Foram testados 5 tempos de moagem: 20, 30, 40, 50 e 60 minutos, a fim de determinar qual o tempo que indica a melhor granulometria.

Em seguida, iniciou-se a etapa de caracterização da cinza da casca de arroz, que consistiu em se determinar: a sua superfície específica; as suas densidades aparente e absoluta; o diâmetro médio das partículas; os índices de atividade pozolânica com o cimento e com a cal; a sua perda ao fogo; e a sua composição química. Realizou-se também o ensaio de difração de raios-X, para determinar a morfologia da amostra.

\subsection{Metodologia}

Na primeira etapa foi realizada a caracterização físico-química da CCA. Na segunda, verificou-se a influência da CCA na resistência à compressão de argamassas com o objetivo de se determinar a sua faixa ótima de dosagem. A terceira etapa consistiu em avaliar a influência da dosagem da CCA no concreto submetido à cura térmica a vapor, variando-se a porcentagem de substituição do cimento por CCA no concreto em $0 \%$, $5 \%$ e $10 \%$, em massa. A influência da cura térmica nas propriedades mecânicas de concretos com CCA foi analisada com o objetivo de verificar o comportamento da CCA em matrizes a base de cimento Portland quando submetidos à cura térmica, já que segundo a bibliografia as reações hidratação do cimento são aceleradas pelo aumento da temperatura de cura.

\subsubsection{Estudo para a Determinação da Porcentagem Ótima de Adição de CCA na Argamassa}

Os traços utilizados para a composição das argamassas são apresentados na tabela 1. Além de um traço controle sem adição da CCA, foram elaboradas mais 5 dosagens, com diferentes porcentagens de substituição do cimento por CCA, em massa. A relação água/(cimento+cinza) foi fixada em 0,4 para todos os casos.

A adoção do uso do superplastificante teve o intuito de melhorar a trabalhabilidade da argamassa, uma vez que esta é reduzida pelo acréscimo de materiais com granulometria muito fina, além de que a presença da cinza leva a uma hidratação mais rápida da mistura. Sua dosagem foi fixada em $1 \%$ da soma da massa de cimento à massa da cinza.

As amostras foram submetidas a ensaios de resistência à compressão aos 7 e 28 dias de cura em câmara úmida. Os resultados obtidos com as argamassas foram tomados como base para a escolha dos traços de concreto.

Tabela 1: Composição da argamassa $\left(\mathrm{kg} / \mathrm{m}^{3}\right)$.

\begin{tabular}{c|c|c|c|c|c|c}
\hline \multirow{2}{*}{ Material } & \multicolumn{7}{|c}{ Traços } \\
\cline { 2 - 7 } & $0 \%$ & $5 \%$ & $7,5 \%$ & $10 \%$ & $12,5 \%$ & $15 \%$ \\
& CCA & CCA & CCA & CCA & CCA & CCA \\
\hline Cimento & 509,3 & 483,8 & 471,1 & 458,4 & 445,6 & 432,9 \\
\hline CCA & 0 & 25,5 & 38,2 & 50,9 & 63,7 & 76,4 \\
\hline Areia & \multicolumn{7}{|c}{1527,9} \\
\hline a/(c+CCA) & \multicolumn{7}{|c}{0,40} \\
\hline
\end{tabular}




\subsubsection{Estudo da Composição do Concreto com Adição de CCA}

A tabela 2 mostra os traços utilizados na composição dos concretos estudados. As dosagens de CCA foram de $0 \%, 5 \%$ e $10 \%$, adotando-se o mesmo critério de substituição realizado no estudo da dosagem das argamassas.

Os teores de superplastificante adotados foram de: $0,2 \%$ da massa de cimento, para o traço sem CCA; $0,2 \%$ da soma da massa de cimento com a de CCA, para o traço com $5 \%$ de substituição de cimento por cinza; $0,3 \%$ da soma da massa de cimento com a de CCA, para o traço com $10 \%$ de substituição. O abatimento para cada traço foi fixado em $120 \pm 20 \mathrm{~mm}$.

Tabela 2: Composição do concreto $\left(\mathrm{kg} / \mathrm{m}^{3}\right)$.

\begin{tabular}{c|c|c|c}
\hline \multirow{2}{*}{ Material } & \multicolumn{3}{|c}{ Traços } \\
\cline { 2 - 4 } & $0 \%$ CCA & $5 \%$ CCA & $10 \%$ CCA \\
\hline Cimento & 490,0 & 465,5 & 441,0 \\
\hline CCA & 0,0 & 24,5 & 49,0 \\
\hline Areia & \multicolumn{3}{|}{} \\
\hline Brita & \multicolumn{3}{|}{051,7} \\
\hline a/(c+CCA) & \multicolumn{3}{|c}{$0,42,3$} \\
\hline
\end{tabular}

Foram moldados corpos de prova (CPs) cilíndricos com dimensões 100x200 mm, com adensamento em mesa vibratória, seguindo as recomendações da NBR 5738 [5] , sendo uma parte levada para a cura úmida e a outra destinada à cura térmica. Após a desmoldagem e capeamento dos corpos de prova, realizou-se a cura em câmara úmida por 7 e 28 dias, seguido dos ensaios realizados conforme as seguintes normas da ABNT:

- determinação da Resistência à Compressão axial, aos 7 e 28 dias, de acordo com a NBR 5739 [6], com a realização do capeamento dos CPs por meio de um composto de enxofre e pozolana;

- resistência à Tração, segundo a NBR 7222 [7];

- módulo de Elasticidade, conforme a NBR 8522 [8].

\subsubsection{Cura Térmica do Concreto}

Os CPs utilizados para a cura térmica foram vedados com filme plástico de modo a impedir a perda de umidade durante o processo de cura. A temperatura foi monitorada por meio de termopares instalados em três CPs. Para isso, foram colocados tubos de cobre de $100 \mathrm{~mm}$ no interior do CP; nesses tubos, preenchidos com óleo, foram introduzidos os termopares; a seguir, os tubos foram vedados com massa de calafetar na parte inferior. A captação dos dados foi realizada por meio de multímetros digitais associados a um sistema de aquisição automático, colocados na lateral do equipamento de cura. As leituras foram feitas em intervalos de 5 min.

Após este procedimento, os CPs foram imediatamente colocados no equipamento de cura térmica, que já se encontrava na temperatura determinada para o ensaio, definida em $80^{\circ} \mathrm{C}$. A cura foi realizada em ambiente saturado por vapor, nessa temperatura e de forma constante, tendo-se uma pequena variação apenas no instante em que as amostras foram retiradas para os ensaios. A retirada das amostras foi feita em intervalos de 1 hora, dentro de um ciclo de cura de duração de 6 horas. 


\section{RESULTADOS E DISCUSSÃO}

\subsection{Caracterização da CCA}

A figura 1 mostra a evolução da temperatura de queima da casca de arroz ao longo de 36 horas. Pode-se observar que a temperatura máxima é de quase $850^{\circ} \mathrm{C}$ e que a temperatura permanece acima dos $600^{\circ} \mathrm{C}$ por aproximadamente 18 horas.

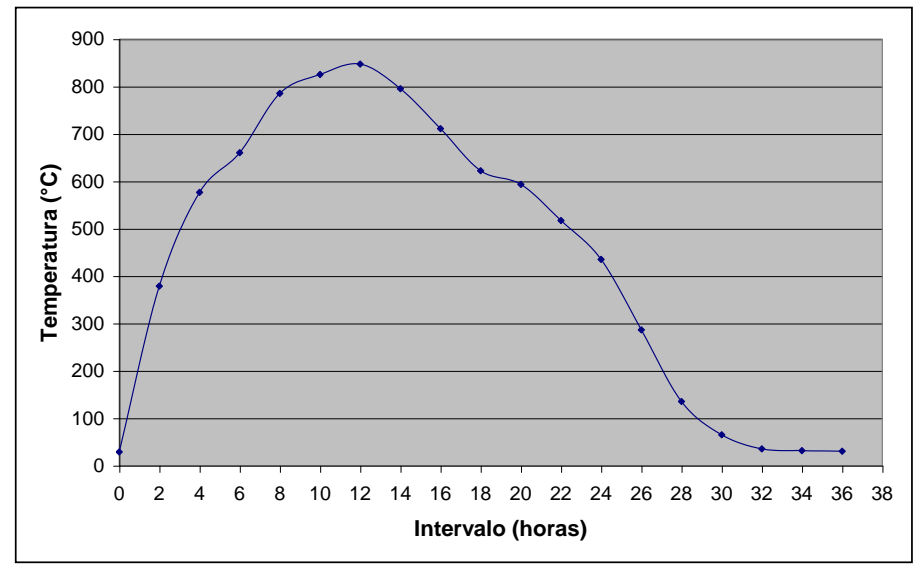

Figura 1: Evolução da temperatura de queima da casca de arroz.

A seguir apresentam-se os resultados da caracterização físico-química da CCA. A tabela 3 mostra como se dá o aumento da superfície específica e a diminuição do diâmetro médio das partículas com o aumento do tempo de moagem, através de ensaio de granulometria a laser.

De acordo com TASHIMA et al. [3] , a CCA tem como um dos maiores componentes químicos a sílica $\left(\mathrm{SiO}_{2}\right)$, estando em aproximadamente $74 \%$ a $97 \%$ em sua composição, independente do processo de queima a qual foi submetida.

O teor de $\mathrm{SiO}_{2}$ observado foi de 92,99\%, próximo ao valor encontrado por DELLA et al. [9], que foi de $96,65 \%$, enquanto que ZAIN et al. [10] obtiveram valores entre 79 e $87 \%$ e BEZERRA [11], 83,41\%. Estes resultados indicam que a CCA apresenta composição química favorável para que seja considerada um material pozolânico. 30 minutos.

A figura 2 mostra a distribuição granulométrica das partículas de CCA moídas durante o período de

Tabela 3: Características físicas da CCA.

\begin{tabular}{c|c|c}
\hline $\begin{array}{c}\text { Tempo de } \\
\text { moagem } \\
(\mathbf{m i n})\end{array}$ & $\begin{array}{c}\text { Superfície especí- } \\
\text { fica }\left(\mathbf{c m}^{\mathbf{2}} \mathbf{/ g}\right)\end{array}$ & $\begin{array}{c}\text { Diâmetro médio } \\
(\boldsymbol{\mu m})\end{array}$ \\
\hline 20 & 15.698 & 14,56 \\
\hline 30 & 17.302 & 12,38 \\
\hline 40 & 20.894 & 9,19 \\
\hline 50 & 22.576 & 7,85 \\
\hline 60 & 23.243 & 7,34 \\
\hline
\end{tabular}




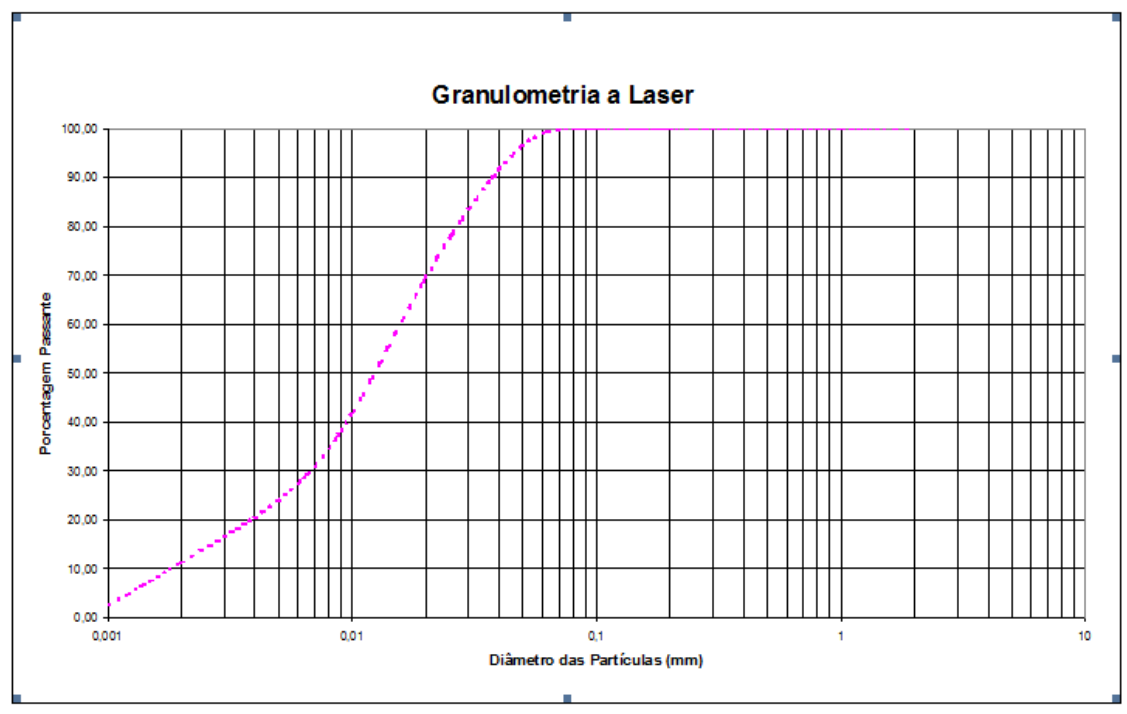

Figura 2: Distribuição granulométrica da CCA moída durante o período de 30 minutos.

A tabela 4 apresenta as características físicas e químicas da amostra de CCA moída pelo período de 30 minutos. A destacar, os índices de atividades pozolânicas ficaram abaixo dos especificados pela NBR-12653 [9].

Tabela 4: Características físicas e químicas da CCA moída em 30 minutos.

\begin{tabular}{|c|c|c|c|c|}
\hline \multicolumn{5}{|c|}{$\begin{array}{c}\text { Especificações } \\
\text { NBR-12653 (Mat. Pozol.) }\end{array}$} \\
\hline & & & $\min$. & máx. \\
\hline \multicolumn{2}{|c|}{ Finura Peneira $325 \quad$ (\% retida) } & 3,4 & - & 34,0 \\
\hline \multicolumn{2}{|c|}{ Superf. espec. Blaine $\quad\left(\mathrm{cm}^{2} / \mathrm{g}\right)$} & 17302 & - & - \\
\hline \multicolumn{2}{|c|}{ Diâmetro dos grãos (micras) } & 12,38 & - & - \\
\hline \multicolumn{2}{|c|}{ Densidade aparente $\quad\left(\mathrm{g} / \mathrm{cm}^{3}\right)$} & 0,40 & - & - \\
\hline \multicolumn{2}{|c|}{ Densidade absoluta $\quad\left(\mathrm{g} / \mathrm{cm}^{3}\right)$} & 2,16 & - & - \\
\hline \multirow{3}{*}{$\begin{array}{c}\text { Índices } \\
\text { atividade } \\
\text { pozolânica }\end{array}$} & Água requerida $(\%)$ & 114,6 & - & 110,0 \\
\hline & Com cimento $(\%)$ & 60,7 & 75,0 & - \\
\hline & Com cal $(\%)$ & 4,9 & 6,0 & - \\
\hline \multicolumn{2}{|c|}{ Umidade (\%) } & 1,90 & - & 3,00 \\
\hline \multirow{13}{*}{$\begin{array}{c}\text { Análise } \\
\text { Química } \\
(\%)\end{array}$} & Perda ao fogo & 2,36 & - & 6,0 \\
\hline & Insolúveis & 91,93 & - & - \\
\hline & $\mathrm{SiO}_{2}$ & 92,99 & - & - \\
\hline & $\mathrm{Fe}_{2} \mathrm{O}_{3}$ & 0,43 & - & - \\
\hline & $\mathrm{Al}_{2} \mathrm{O}_{3}$ & 0,18 & - & - \\
\hline & $\mathrm{CaO}$ & 1,03 & - & - \\
\hline & $\mathrm{MgO}$ & 0,35 & - & - \\
\hline & $\mathrm{SO}_{3}$ & 0,10 & - & 5,0 \\
\hline & $\mathrm{Al}_{2} \mathrm{O}_{3}+\mathrm{Fe}_{2} \mathrm{O}_{3}$ & 0,61 & - & - \\
\hline & $\mathrm{SiO}_{2}+\mathrm{Al}_{2} \mathrm{O}_{3}+\mathrm{Fe}_{2} \mathrm{O}_{3}$ & 93,50 & 70,00 & - \\
\hline & $\mathrm{Na}_{2} \mathrm{O}$ & 0,02 & - & - \\
\hline & $\mathrm{K}_{2} \mathrm{O}$ & 0,72 & - & - \\
\hline & Equiv alcalino $\mathrm{Na}_{2} \mathrm{O}$ & 0,49 & - & - \\
\hline
\end{tabular}

A figura 3 apresenta o resultado do ensaio de difração de raios-X, realizado na amostra estudada. Como pode ser observado, trata-se de um material amorfo, caracterizado pelo desvio na linha base entre os ângulos de 15 e $30^{\circ}$. Analisando a temperatura de queima e o tempo de exposição a essa temperatura, era de esperar que a cinza obtida apresentasse algumas fases cristalinas de $\mathrm{SiO}_{2}$ (cristobalita e/ou tridimita), entretanto, isso não foi observado. 


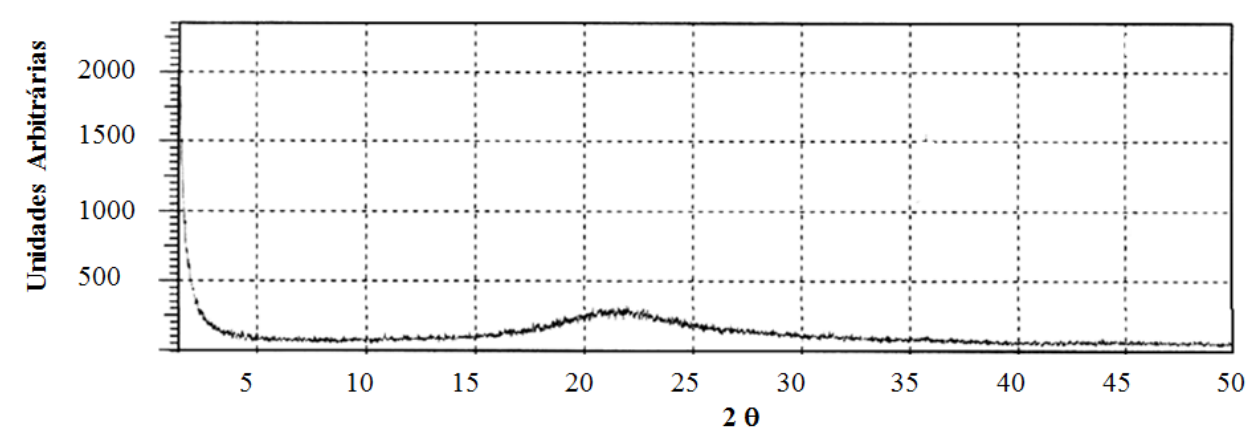

Figura 3: Ensaio de difração de raios-X.

ZAIN et al. [10] também observaram sílica em estado amorfo, a uma temperatura de combustão constante de 500 a $700^{\circ} \mathrm{C}$ para as primeiras 2 horas e, em seguida, resfriando de maneira uniforme até 48 horas. PAYÁ et al. [13], entretanto, verificaram a presença de picos devido à presença de formas de sílica cristalina, cristobalita e tridimita, sugerindo que a temperatura de incineração foi superior a $900^{\circ} \mathrm{C}$ e/ou a temperatura na gama de $700-900^{\circ} \mathrm{C}$ foi mantida durante um longo período.

\subsection{Resistência à compressão de CPs de argamassa}

A figura 4 mostra a relação entre a resistência à compressão de corpos de prova e o tempo de moagem da CCA e a porcentagem de substituição do cimento por CCA, após 7 e 28 dias de cura.

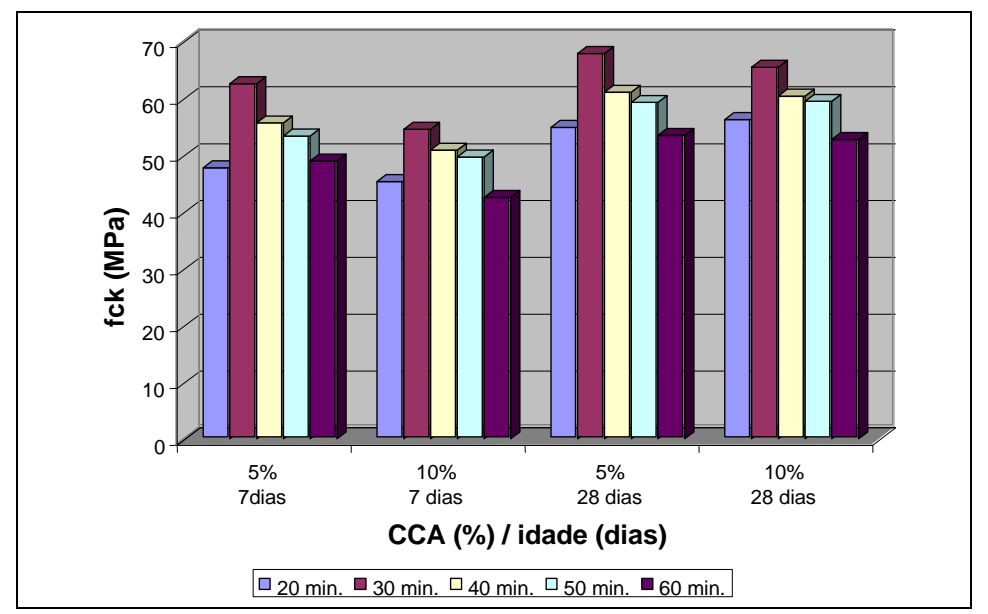

Figura 4: Resistência à compressão das argamassas, tempo de moagem e teor de substituição de cimento por CCA.

Os resultados indicam que a melhor granulometria foi aquela obtida com o tempo de moagem correspondente a 30 minutos. A partir deste ponto, foi este o tempo de moagem adotado para as cinzas utilizadas na elaboração das outras argamassas e do concreto.

A figura 5 mostra os resultados de resistência à compressão axial das argamassas moldadas com diferentes teores de substituição do cimento por CCA. 


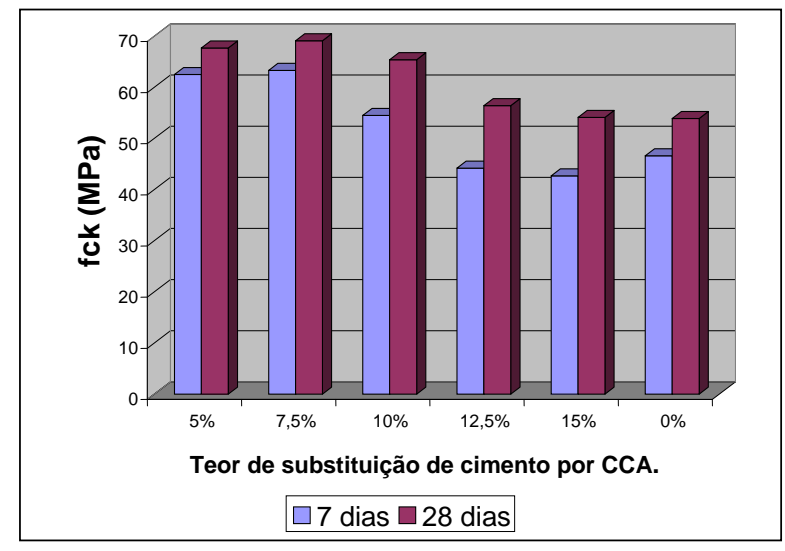

Figura 5: Relação entre dosagem de CCA e resistência à compressão.

Os dados mostram que as dosagens com melhores resultados de ganho de resistência estão entre 5 e $10 \%$. Dosagens maiores só alcançam ganhos de resistência com relação à argamassa controle a partir dos 28 dias. TASHIMA [14] verificou que a substituição de cimento por CCA, nas porcentagens de 5\%, 10\% e 15\%, aumentou a resistência à compressão da argamassa, sendo este aumento proporcional ao aumento da porcentagem de substituição, fato este que pode ser explicado por se tratar da introdução de material pozolânico, que além de seu efeito químico, atua também diminuindo o tamanho dos poros.

\subsection{Resistência à compressão de CPs de concreto}

\subsubsection{Cura em câmara úmida}

A figura 6 mostra a evolução da resistência à compressão axial dos corpos de prova cilíndricos de concreto, com $10 \mathrm{~cm}$ de diâmetro e 20 de comprimento, para os traços controle e com 5\% e 10\% de substituição de cimento por CCA.

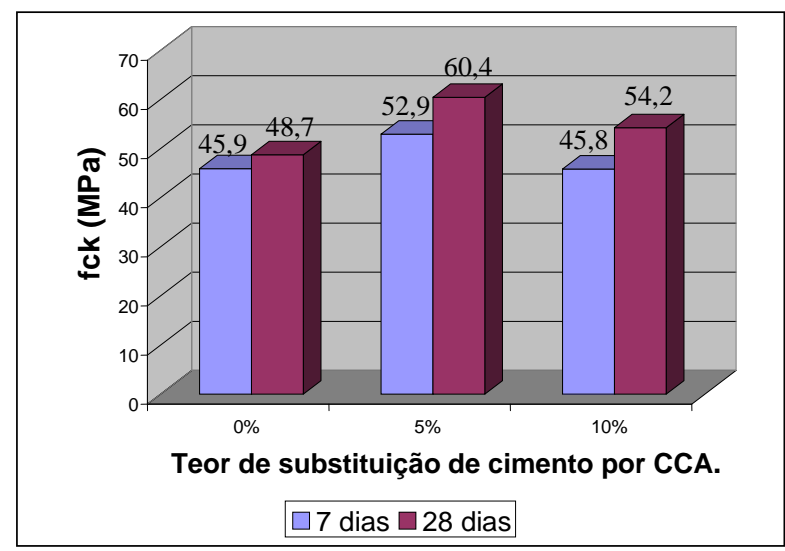

Figura 6: Relação entre o teor de substituição do cimento por CCA e resistência à compressão.

As melhores características de resistência à compressão axial foram observadas nos traços com $5 \%$ de CCA, tanto para os 7 dias quanto para os 28 dias de idade. SILVA et al. [15] observaram que o concreto controle apresentou menores resistências ao longo do tempo em relação aos concretos com adições de $10 \%$ de CCA.

Também são apresentados os resultados de resistência à tração, obtidos por meio dos ensaios de compressão diametral (Figura 7), e do módulo de elasticidade (Figura 8), realizados nas mesmas idades. 


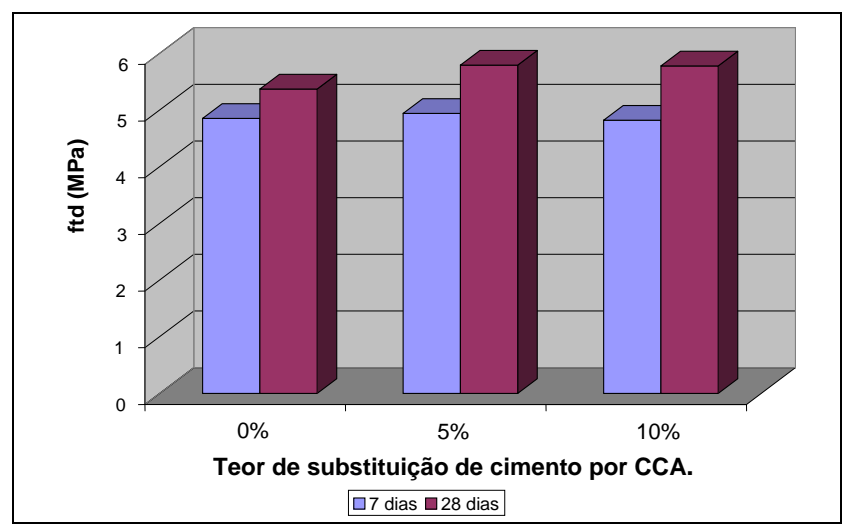

Figura 7: Relação entre o teor de substituição do cimento por CCA e resistência à tração (ensaio de compressão diametral).

Para o caso da resistência à tração obtida por meio do ensaio de compressão diametral, observa-se que a presença da CCA não proporciona ganhos de resistência, independente da idade e do teor de substituição.

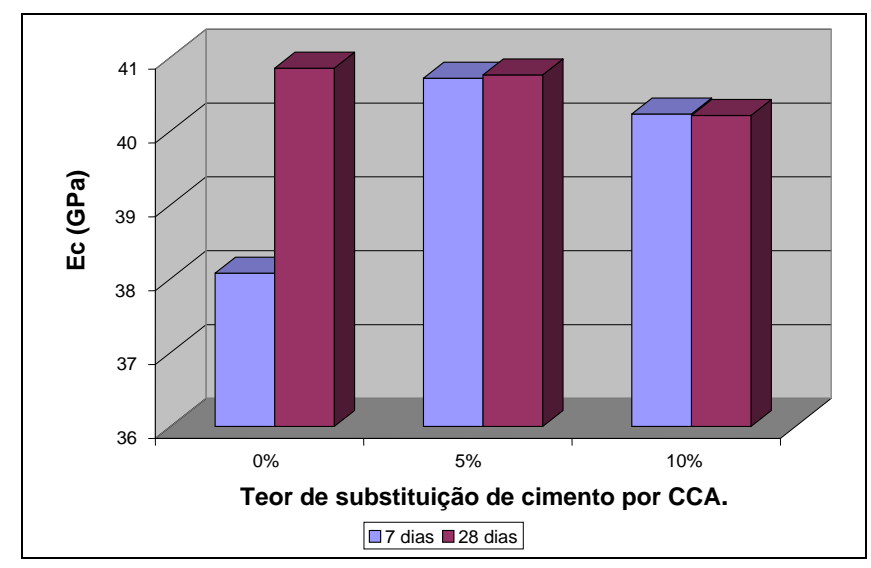

Figura 8: Relação entre o teor de substituição do cimento por CCA e o módulo de elasticidade.

Em relação ao módulo de elasticidade, os valores obtidos para os três traços se situaram entre 40 e 41 GPa, não importando a idade ou o teor de substituição de cimento por CCA. Os dados se mostram coerentes quando os maiores valores de módulo de elasticidade são comparados com os de resistência à compressão axial para o teor de 5\% de substituição. SILVA et al. [15] observaram que o módulo de elasticidade de concretos com adições minerais não sofre aumentos significativos quando comparados com os aumentos observados para a resistência à compressão.

\subsubsection{Cura térmica}

As tabelas 5, 6 e 7 mostram os valores médios (M) de tensão de compressão axial, de tração e de módulo de elasticidade obtidos durante o ciclo de cura térmica de 6 horas, bem como o desvio padrão (DP) e o coeficiente de variação $(\mathrm{CV})$. Pode-se notar que em nenhum dos casos o CV foi maior que $25 \%$, garantindo a qualidade dos resultados obtidos. 
PEREIRA, A. M.; SILVA, C. A. R.; QUEIROZ, D. C. A.; MORAES, M. J. B.; MELGES, J. L. P.; TASHIMA, M. M.; AKAS AKI, J. L. revista Matéria, v.20, n.1, pp. 227-238, 2015.

Tabela 5: Valores para a resistência à compressão axial

\begin{tabular}{|c|c|c|c|c|c|c|c|c|c|}
\hline \multicolumn{9}{|c|}{ Resistência à compressão axial (MPa) } \\
\hline \multirow{2}{*}{ Ciclo } & \multicolumn{3}{|c|}{ Controle } & \multicolumn{3}{c|}{ 5\%CCA } & \multicolumn{3}{c|}{$\mathbf{1 0 \% C C A ~}$} \\
\cline { 2 - 10 } & $\mathbf{M}$ & DP & CV & M & DP & CV & M & DP & CV \\
\hline $\mathbf{1 h}$ & 1,82 & 0,43 & 0,24 & 1,67 & 0,19 & 0,11 & 1,79 & 0,41 & 0,23 \\
\hline $\mathbf{2 h}$ & 14,54 & 1,10 & 0,08 & 13,13 & 0,21 & 0,02 & 12,21 & 0,68 & 0,06 \\
\hline $\mathbf{3 h}$ & 19,59 & 0,93 & 0,05 & 13,19 & 0,19 & 0,01 & 18,56 & 1,11 & 0,06 \\
\hline $\mathbf{4 h}$ & 21,69 & 1,07 & 0,05 & 19,90 & 2,28 & 0,11 & 17,49 & 2,13 & 0,12 \\
\hline $\mathbf{5 h}$ & 21,81 & 0,65 & 0,03 & 21,39 & 2,21 & 0,10 & 18,00 & 1,28 & 0,07 \\
\hline $\mathbf{6 h}$ & 24,06 & 1,92 & 0,08 & 18,72 & 0,67 & 0,04 & 21,35 & 1,68 & 0,08 \\
\hline
\end{tabular}

Tabela 6: Valores para a tração (ensaio de compressão diametral).

\begin{tabular}{|c|c|c|c|c|c|c|c|c|c|}
\hline \multicolumn{7}{|c|}{ Resistência à tração na compressão diametral (MPa) } \\
\hline \multirow{2}{*}{ Ciclo } & \multicolumn{3}{|c|}{ Controle } & \multicolumn{3}{|c|}{$\mathbf{5 \% C C A}$} & \multicolumn{3}{c|}{$\mathbf{1 0 \% C C A ~}$} \\
\cline { 2 - 11 } & $\mathbf{M}$ & DP & CV & M & DP & CV & M & DP & CV \\
\hline $\mathbf{1 h}$ & 0,10 & 0,01 & 0,10 & 0,13 & 0,00 & 0,00 & 0,14 & 0,01 & 0,07 \\
\hline $\mathbf{2 h}$ & 1,57 & 0,12 & 0,08 & 1,58 & 0,18 & 0,11 & 1,81 & 0,16 & 0,09 \\
\hline $\mathbf{3 h}$ & 2,46 & 0,03 & 0,01 & 2,50 & 0,18 & 0,07 & 2,40 & 0,09 & 0,04 \\
\hline $\mathbf{4 h}$ & 2,67 & 0,17 & 0,06 & 2,61 & 0,03 & 0,01 & 2,51 & 0,08 & 0,03 \\
\hline $\mathbf{5 h}$ & 2,89 & 0,36 & 0,12 & 2,83 & 0,15 & 0,05 & 3,01 & 0,04 & 0,01 \\
\hline $\mathbf{6 h}$ & 3,10 & 0,21 & 0,07 & 2,81 & 0,11 & 0,04 & 3,03 & 0,10 & 0,03 \\
\hline
\end{tabular}

Considerando-se que não foi possível aplicar a carga mínima exigida pelo equipamento em função da baixa resistência à compressão na primeira ruptura, os valores de módulo de elasticidade não foram apresentados para a primeira hora do ciclo.

Tabela 7: Valores para módulo de elasticidade.

\begin{tabular}{|c|c|c|c|c|c|c|c|c|c|}
\hline \multicolumn{9}{|c|}{ Módulo de Elasticidade (GPa) } \\
\hline \multirow{2}{*}{ Ciclo } & \multicolumn{3}{|c|}{ Controle } & \multicolumn{3}{c|}{ 5\%CCA } & \multicolumn{3}{c|}{$\mathbf{1 0 \% C C A ~}$} \\
& $\mathbf{M}$ & DP & CV & M & DP & CV & M & DP & CV \\
\hline $\mathbf{2 h}$ & 12,93 & 1,14 & 0,09 & 13,57 & 1,06 & 0,08 & 12,73 & 0,18 & 0,01 \\
\hline $\mathbf{3 h}$ & 20,14 & 1,57 & 0,08 & 17,65 & 0,80 & 0,05 & 15,44 & 1,29 & 0,08 \\
\hline $\mathbf{4 h}$ & 21,79 & 1,80 & 0,08 & 21,41 & 0,07 & 0,00 & 15,95 & 0,45 & 0,03 \\
\hline $\mathbf{5 h}$ & 22,50 & 0,85 & 0,04 & 22,05 & 1,40 & 0,06 & 19,79 & 1,18 & 0,06 \\
\hline $\mathbf{6 h}$ & 22,65 & 1,82 & 0,08 & 22,08 & 0,64 & 0,03 & 20,41 & 1,15 & 0,06 \\
\hline
\end{tabular}

Ao contrário do que foi visto para a cura úmida, em relação ao traço com 5\% de CCA, onde foi observado um aumento de resistência à compressão axial, em relação ao traço controle, para a cura térmica, os resultados se mostraram ligeiramente inferiores em relação ao traço controle. Também não foram observados ganhos expressivos de resistência à compressão diametral e do módulo de elasticidade para os traços com adição de CCA, submetidos à cura térmica. Fica evidente que maiores estudos serão necessários para definir melhor o processo de hidratação que ocorre no concreto com CCA, quando submetido à cura térmica.

\section{CONCLUSÕES}

Este trabalho tratou da utilização da cinza de casca de arroz (CCA) em concretos e argamassas, por meio da queima não controlada da casca. Além disso, avaliou-se a influência da temperatura de cura nas propriedades mecânicas do concreto.

A substituição de cimento Portland por cinza se mostrou satisfatória para os teores de 5\% e $10 \%$ nas 
dosagens de concreto e de argamassa, no que diz respeito ao ganho de resistência à compressão axial, chegando a percentuais de $24 \%$ para o concreto e $28 \%$ para a argamassa, na idade de 28 dias, considerando a cura úmida. Para isso, a granulometria ideal para o uso da CCA foi de aproximadamente $12 \mu \mathrm{m}$, obtida após um tempo de moagem de 30 minutos.

O uso de maiores porcentagens de substituição de cimento por CCA (de 10 a 15\%), em argamassas, não proporcionou grandes ganhos de resistência se comparados ao traço controle, aos 28 dias. No entanto, observou-se um ganho de resistência significativo nas primeiras idades.

Considerando-se o concreto submetido à cura úmida, foram obtidos maiores valores de resistência à compressão axial e diametral nos traços com um teor de $5 \%$ de substituição de cimento por CCA. Já com relação ao módulo de elasticidade, os traços com CCA apresentaram reduções pouco expressivas.

Em relação à cura térmica, foram observados valores de resistência mecânica similares aos obtidos para os concretos sem adição da CCA. Entretanto, é importante ressaltar que os concretos com CCA possuem uma menor quantidade de cimento Portland, fato que indica que a CCA tem um papel fundamental como material pozolânico, além de contribuir com o fechamento dos poros do concreto.

\section{AGRADECIMENTOS}

Os autores agradecem:

- À Holcim Brasil, pela doação do cimento;

- À Sika Brasil, pela doação do superplastificante;

- À CAPES (Coordenação de Aperfeiçoamento de Pessoal de Nível Superior);

- Ao CNPq (Conselho Nacional de Desenvolvimento Científico e Tecnológico).

\section{BIBLIOGRAFIA}

[1] INSTITUTO BRASILEIRO DE GEOGRAFIA E ESTATÍSTICA, http://www.ibge.gov.br. Acessado em fevereiro de 2014.

[2] FUNDAÇÃO ESTADUAL DE PROTEÇÃO AMBIENTAL, http://www.fepam.rs.gov.br. Acessado em fevereiro de 2014.

[3] TASHIMA, M. M., SILVA, C. A. R. L., AKASAKI, J. L. "Concreto com adição de cinza de casca de arroz (CCA) obtida através de um processo de combustão não controlada”, In: XXXI Jornada Sudamericanas de Ingenieria Estructural, Mendonza, Argentina, 2004.

[4] SALVADOR FILHO, J. A. A. Cura térmica dos concretos de alto desempenho: análise das propriedades mecânicas utilizando o método da maturidade, Dissertação de M.Sc, FEIS - UNESP, Ilha Solteira, SP, Brasil, 2001.

[5] ASSOCIAÇÃO BRASILEIRA DE NORMAS TÉCNICAS (2008). NBR 5738: concreto - procedimento para moldagem e cura de corpos-de-prova, Rio de Janeiro, ABNT - Associação Brasileira de Normas Técnicas.

[6] ASSOCIAÇÃO BRASILEIRA DE NORMAS TÉCNICAS (2007). NBR 5739: Concreto - ensaio de compressão de corpos-de-prova cilíndricos: procedimento. Rio de Janeiro, ABNT - Associação Brasileira de Normas Técnicas.

[7] ASSOCIAÇÃO BRASILEIRA DE NORMAS TÉCNICAS (2011). NBR 7222: Argamassa e concreto Determinação da resistência à tração por compressão diametral: procedimento, Rio de Janeiro, ABNT Associação Brasileira de Normas Técnicas.

[8] ASSOCIAÇÃO BRASILEIRA DE NORMAS TÉCNICAS (2008). NBR 8522: Concreto: Determinação do módulo de deformação estática e diagrama tensão-deformação: procedimento. Rio de Janeiro, ABNT Associação Brasileira de Normas Técnicas.

[9] DELLA, V. P., KÜHN, I., HOTZA, D. "Caracterização de cinza de casca de arroz para uso como matéria-prima na fabricação de refratários de sílica”, Química Nova, v. 24, n. 6, pp.778-782, 2001.

[10] ZAIN, M. F. M., ISLAM, M. N., MAHMUD, F, et al., "Production of rice husk ash for use in concrete as a supplementary cementitious material”, Construction and Building Materials, v. 25, pp. 798-805, 2011.

[11] BEZERRA, I. M. T. Cinza da casca do arroz utilizada em argamassas de assentamento e revestimento, dissertação de M.Sc., UFCG, Campina Grande, PB, Brasil, 2010. 
[12] ASSOCIAÇÃO BRASILEIRA DE NORMAS TÉCNICAS (2012). NBR: 12653: Materiais pozolânicos - Especificação. Rio de Janeiro, ABNT - Associação Brasileira de Normas Técnicas.

[13] PAYÁ, J., MONZÓ, J., BORRACHERO, M. V., et al.,"Studies on cristalline rice husk ashes and the activation of their pozzolanic properties", In: WOOLLEY, G. R., GOUMANS, J. J. J. M., WAINWRIGHT, P. J., Waste materials in construction wascon 2000, Amsterdam, Pergamon, pp. 493-503, 2000.

[14] TASHIMA, M. M. Cinza de casca de arroz altamente reativa: método de produção, caracterização fisico-química e comportamento em matrizes de cimento Portland, dissertação de M.Sc., FEIS/UNESP, Ilha Solteira, SP, Brasil, 2006.

[15] SILVA, E. J., PRADO, L. P., AKASAKI, J. L., et al., "Avaliação da cinza de casca de arroz (sem sofrer processo de moagem) quando adicionado ao concreto", In: ELECS 2009 - V Encontro Nacional e III Encontro Latino-americano sobre Edificações e Comunidades Sustentáveis, Recife, PE, Brasil, 28-30 de outubro de 2009. 